\title{
Processos e materialização da agricultura urbana como ativismo na cidade de São Paulo: o caso da Horta das Corujas
}

\author{
Processes and materialization of urban agriculture as activism \\ in the city of São Paulo: the case of the Corujas Community Garden
}

Gustavo Nagib [l]

\section{Resumo}

Este artigo apresenta a agricultura urbana como ativismo na cidade de São Paulo a partir da consolidação da rede "Hortelões Urbanos", em 2011, que impulsionou, consequentemente, a materialização da primeira horta comunitária em 2012: a Horta das Corujas. Para a realização deste estudo de caso, seguiu-se a metodologia da pesquisa-ação e atentou-se ao processo histórico que conduziu à materialização da referida horta, compreendendo-se as transformações socioespaciais tanto da praça pública quanto dos bairros onde ela se localiza. Esse modelo de ativismo local tem impulsionado mudanças legislativas e culturais em toda a cidade, e a sua análise conduz a novas reflexões sobre o espaço urbano e atualiza o debate acerca do direito à cidade.

Palavras-chave: agricultura urbana; horta comunitária; ativismo; corujas; direito à cidade.

\begin{abstract}
This article presents urban agriculture as activism in the city of São Paulo based on the consolidation of a network called "Hortelões Urbanos" in 2011, which contributed to the materialization of the first community garden in 2012: the Corujas Community Garden. To conduct this case study, we used the methodology of action research and focused on the historical process that led to the materialization of that community garden, examining the socio-spatial transformations of both the public square and the neighborhoods where it is located. This model of local activism has stimulated legislative and cultural changes throughout the city, and its analysis leads to new reflections on urban space and updates the debate about the right to the city.
\end{abstract}

Keywords: urban agriculture; community garden; activism; Corujas; right to the city. 


\section{Da metodologia da pesquisa-ação}

Este artigo é fruto de uma pesquisa que seguiu os procedimentos metodológicos da pesquisa-ação:

A pesquisa-ação é um tipo de pesquisa social com base empírica que é concebida e realizada em estrita associação com uma ação ou com a resolução de um problema coletivo e no qual os pesquisadores e os participantes representativos da situação ou do problema estão envolvidos de modo cooperativo ou participativo. (Thiollent, 2011, p. 20)

0 próprio objeto de estudo e a inspiração temática inicial originaram-se do engajamento participativo deste pesquisador com a temática em questão, de seu envolvimento enquanto um dos voluntários da horta estudada, bem como com os movimentos em prol da agricultura urbana na cidade de São Paulo, buscando-se abranger, além da participação, uma ação planejada de caráter socioespacial. Esses quesitos não devem ser confundidos, no entanto, apenas como uma participação ativista. Segundo Thiollent (ibid., pp. 8-9), "a pesquisa-ação pode ser concebida como [...] um caminho ou um conjunto de procedimentos para interligar conhecimento e ação, ou extrair da ação novos conhecimentos". A pesquisa-ação, portanto, não é só uma atividade de intervenção social, já que também exige validação científica e reconhecimento acadêmico. Ainda segundo o referido autor, a crítica de que na pesquisa-ação haja um rebaixamento do nível de exigência acadêmica não é válida, uma vez que pode haver manipulações e demais riscos em qualquer tipo de pesquisa.

Especificamente para o estudo de caso aqui em questão (da Horta das Corujas), a pesquisa-ação revelou-se adequada por ser um

instrumento de trabalho e de investigação com grupos, instituições, coletividades de pequeno ou médio porte, [sendo] possivel estudar dinamicamente os problemas, decisões, ações, negociações, conflitos e tomadas de consciência [que ocorreram] entre os agentes durante 0 processo de transformação da situação. (Ibid., pp. 15-25)

No que se refere ao uso e à análise das falas de entrevistados e dos depoimentos coletados, levou-se em consideração as diferentes percepções "dos acontecimentos mais comuns", para "tentar entender o que significam e ver se surgem explicações entre eles" (Jacobs, 2013, p. 13), e considerou-se que:

Muitas inferências são baseadas no senso comum e, algumas delas, no chamado "bom senso", considerado por Antônio Gramsci como núcleo racional da sabedoria popular [...]. As inferências em linguagem comum são controláveis ou compreendidas em função do contexto sociocultural no qual elas são proferidas. Muitas vezes, para as entendermos, isto é, reconhecermos seu fundo de racionalidade (ou de irracionalidade), precisamos explicitar seus pressupostos ou fazer que o interlocutor os explicite. [...] Quando se trata de uma ação de caráter cultural, educacional ou político, os pesquisadores e participantes devem estar em condição de fazer uma avaliação realista dos objetivos e dos efeitos e não ficarem satisfeitos no nível das declarações de intenção (como muitas vezes ocorre). 0 desenrolar 
e a avaliação de uma ação cultural são talvez mais difusos e menos evidentes do que no caso de atos técnicos bem definidos. (Thiollent, 2011, pp. 45-50)

A escolha das questões, que buscaram contemplar a fase exploratória da pesquisa-ação, foi norteada por algumas perguntas iniciais com o intuito de melhor compreender o grupo enquanto parte de um processo de produção e de vivência coletivas:

De acordo com o princípio da participação, são destacadas as condições da colaboração entre pesquisadores e pessoas ou grupos envolvidos na situação investigada. Quem são essas pessoas ou grupos em termos sociais e culturais? A que interesses políticos estão vinculados? Já participaram em experiências semelhantes? Com êxito ou fracasso? Dentro da imaginação popular, como são representados os problemas e possíveis soluções? Que tipo de crença está interferindo? Existe vontade de participar? De que forma? Existe dificuldade de compreensão ou de expressão? (Ibid., p. 57)

0 artigo foi elaborado a partir dos tópicos temáticos mais significativos de cada aspecto do estudo de caso: (a) o processo de concepção e pré-materialização da Horta das Corujas; (b) as pessoas envolvidas, dando destaque aos principais agentes promotores da ação de materialização da horta; (c) a caracterização física, histórica e socioeconômica da área de estudo; (d) os motivos de escolha do lugar de instalação da horta; (e) os meios de divulgação das ações realizadas na horta; (f) as relações estabelecidas com o espaço público; (g) a relevância dos mutirões, da estética e do consumo seguro.

\section{Do processo histórico}

A Horta das Corujas é uma horta comunitária em espaço público, localizada no bairro da Vila Beatriz (distrito do Alto de Pinheiros, vizinho à Vila Madalena, no território da subprefeitura de Pinheiros), na zona Oeste da cidade de São Paulo. Como a praça Dolores Ibárruri é popularmente conhecida como "praça das Corujas", em referência ao córrego de mesmo nome que limita sua face leste, a horta, ali estabelecida, foi consequentemente batizada de "Horta das Corujas".

Isidora Dolores Ibárruri Gómez (conhecida como La Pasionaria), nascida dia 9 de dezembro de 1895, em Gallarta, uma localidade de Biscaia (província do País Basco) na Espanha. Seu nome verdadeiro era "Isidora Ibárruri Gómez". [...]. Casou-se em 1916 com Julián Ruiz e teve seis filhos. Exilou-se na URSS após a vitória de [Francisco] Franco, e regressou à Espanha em 1977, após a morte do general. Foi eleita para o Parlamento e permaneceu líder honorária do Partido Comunista até morrer. Faleceu aos 93 anos de idade, dia 12 de novembro de 1989, em Madri, Espanha [...]. Esta praça, que divide a vila Madalena e [a vila] Beatriz, também é conhecida como "praça das Corujas", devido ao córrego "das Corujas", que corta o referido bairro. (Arquivo Histórico da Prefeitura de São Paulo, 2019)

Cortada pelo córrego das Corujas, que nasce nas proximidades da rua Heitor Penteado e deságua no rio Pinheiros, o loteamento da vila Beatriz foi fundado em 1939. Seus primeiros habitantes eram, em sua maioria, imigrantes portugueses de origem humilde, que se integravam ao núcleo original de Pinheiros a pé, 
pela rua do Futuro (atual rua Natingui), e eram atraídos pelos baixos preços dos terrenos, localizados na "baixada" da vila Madalena (Câmara Municipal de São Paulo, 2016).

A São Paulo Tramway, Light and Power Company (Light) levou a luz elétrica à vila Beatriz apenas em 1950 e, até 1960, quando se inaugurou a primeira linha de ônibus do bairro ao Centro da cidade, a população local dependia do serviço de transporte público que chegava até a vila Madalena; 0 asfalto e a iluminação das vias públicas chegariam apenas em 1967. Na década de 1970, o perfil socioeconômico do bairro começa a se modificar com o avanço de empreendimentos imobiliários voltados para as classes de maior poder aquisitivo. $\mathrm{Na}$ década de 1980, outra grande transformação da paisagem vem com a canalização do córrego das Corujas, que passa a ter 200 metros de seu percurso a céu aberto e o restante, por galerias subterrâneas. Em 2004, a Companhia de Saneamento Básico do Estado de São Paulo (Sabesp) redimensiona a rede de esgoto local e, em 2007, o córrego das Corujas torna-se um dos primeiros 40 córregos limpos da capital, após ser um dos beneficiados pelo Programa Córrego Limpo da Sabesp e da Prefeitura de São Paulo (ibid.; Prefeitura de São Paulo, 2016). A vila Madalena, por sua vez, teve seu povoamento iniciado na década de 1910, quando era denominada "vila dos Farrapos", por conta de seus habitantes de origem humilde. Parte do bairro já foi denominada, no passado, "sítio do Rio Verde", em referência a essa antiga propriedade, cujas terras foram loteadas por José Oswald de Andrade (pai de Oswald de Andrade), no final do século XIX, e que possuía o nome do córrego que limitava uma parte do bairro de Pinheiros dos morros e colinas da vila
Madalena. Seu povoamento inicial deu-se basicamente por imigrantes portugueses (açougueiros, cobradores de bonde, construtores de túmulos dos cemitérios próximos - São Paulo, Araçá e Consolação -, jardineiros, motorneiros, padeiros, sapateiros, servidores da limpeza pública, etc.), atraídos pelo anúncio de que a Light levaria o bonde até a região, mas que adentrou o bairro apenas em 1954 (Azevedo, 1958; Pezzotti, 1998).

Nos anos 1930, a vila Madalena "apresentava um casario esparso, mas difuso por grande parte, ou todo o loteamento" (Langenbuch, 1971, p. 134). "Somente na década de 1950, as ruas de terra começaram a ceder lugar ao asfalto [...]" (Cury, 2004, p. 10). A paisagem do bairro de "pequenas casas, com um quintal atrás onde se plantavam hortaliças, frutas e nas quais se criavam principalmente galinhas" (Squeff, 2002, p. 17), pouco se alterou até as décadas de 1970 e 1980, quando novos empreendimentos imobiliários começaram a lhe atribuir outra configuração, dando início ao processo de verticalização (em contínua expansão ainda nesta segunda década do século XXI) e aumentando o adensamento populacional.

A década de 1970, segundo Squeff (ibid., pp. 21-79), foi bastante simbólica para a história da vila Madalena, pois marcou a chegada, em maior número, dos novos habitantes que conferiram, ao bairro, sua fama de "alternativo", "boêmio", "dos hippies", entre outras designações presentes na oralidade cotidiana dos paulistanos até o presente século XXI. Aqueles novos personagens - notadamente estudantes, artistas e intelectuais - estabeleceram-se na vila Madalena graças aos aluguéis mais baixos (naqueles anos 1970), comparados a outros pontos relativamente próximos ao Centro da 
cidade, e por estar nas imediações da Cidade Universitária (USP): "Na verdade foram eles que deram origem à Vila como ela seria mais tarde; a Vila, dizem seus mais antigos moradores [...], nasceu, sem a menor dúvida, com a chegada dos hippies".

0 processo de "renovação" pelo qual passou a vila Madalena, com o arrasamento das antigas casas - geralmente em lotes estreitos e compridos de 10 metros por 50 metros e separadas por muros baixos de no máximo 1,5 metro de altura (Pezzotti, 1998) -, para dar lugar a "modernos" edifícios, alterou a vida social no bairro. Os empreendimentos imobiliários destes últimos 20-30 anos geralmente expulsam a população mais antiga - tentada a vender seus imóveis às construtoras, ou impossibilitada de pagar o elevado valor dos aluguéis (Verri, 2014) - e aprofundam a fragmentação do espaço, "impondo a segregação como um conteúdo central da urbanização contemporânea da metrópole" (Padua, 2015, p. 89).

Harvey (2014, p. 152) exemplifica o referido processo quando destaca que um grupo comunitário, ao lutar por manter a diversidade de seu bairro, pode se dar conta de que o preço de seus imóveis aumenta quando "os agentes imobiliários propagandeiam para os ricos o 'caráter' multicultural, diversificado e movimentado de seu bairro", e, dessa forma, os moradores originais acabam sendo excluídos do espaço que criaram. A fama que a vila Madalena adquiriu no imaginário paulistano - associada à história do bairro, que agregou estudantes, intelectuais e artistas nos anos 1970 e 1980 - também foi alavancada pelas incursões do mercado imobiliário que, visando ao sucesso comercial de seus empreendimentos, propagandeou e valeu-se da imagem social do bairro para atrair novos moradores, frequentadores e serviços (Verri, 2014).

\section{De "Fazendinha" à praça das Corujas}

A praça Dolores Ibárruri foi criada pelo decreto n. 28.387, de 8 de dezembro de 1989, da prefeita Luiza Erundina. Anteriormente à criação da praça, o local era coloquialmente denominado "Fazendinha" ou "sítio das Corujas". Esses apelidos são fruto do tipo de ocupação que Felipe Martins, também conhecido como "Felipão" ou "Felipe Boiadeiro", fazia da área: criação de animais, com destaque a pôneis, jegues e cavalos.

0 terreno ocupado por Martins era de propriedade da Prefeitura, que, em 1986, durante a administração do prefeito Jânio Quadros, entrou com pedido, na Justiça, de reintegração de posse conquistada apenas em 1991, na administração da prefeita Luiza Erundina. Devido a protestos de moradores para que a Prefeitura deixasse Martins permanecer na área ocupada há cerca de 50 anos, a então administração municipal voltou atrás na decisão. No entanto, em $1^{\circ}$ de março de 1994, já na administração do prefeito Paulo Maluf, a Prefeitura teve a posse reintegrada do terreno, os galpões que Martins havia feito no local foram demolidos, e seus animais foram levados pela Secretaria Municipal da Saúde.

0 boiadeiro Martins, quando da reintegração de posse, tinha cerca de 80 anos e veio a falecer alguns meses depois, em junho. Depoimentos orais e reportagem de um jornal de bairro da época associam sua morte ao 
desgosto de ter sido despejado de sua "Fazendinha". Desde a década de 1980, associações de bairro e políticos locais foram mencionados em reportagens da ocasião como defensores da permanência de Martins no "sítio das Corujas" e por expressarem preocupação sobre 0 destino da área verde. ${ }^{1} 0$ jornal Folha de S.Paulo, por exemplo, publicou uma fala do então presidente do Partido Verde, José Luiz de França Penna, expressando sua preocupação, naquele momento, de que "a burocracia municipal transform[asse] a área verde em um local cheio de concreto". ${ }^{2}$

A reintegração de posse conquistada pela prefeitura na justiça correspondia a 3.800 $\mathrm{m}^{2}$ de uma grande extensão de $24.000 \mathrm{~m}^{2}$ de terras públicas em uma íngreme vertente, cuja baixada beira a parcela aberta do córrego das Corujas. Contudo, a praça criada pelo decreto $n$. 28.387/1989 abrangia todo esse grande terreno. Logo após a saída de Felipe Martins e de seus animais da área por eles ocupada, em 1994, reportagens da época narram que os galpões do boiadeiro foram desmanchados, mas que a prefeitura abandonou a área.

Entre fins dos anos 1990 e início dos anos 2000 , a praça viria a ganhar uma quadra poliesportiva cimentada e postes de iluminação. No ano de 2006, moradores do entorno e lideranças políticas locais começaram a se articular para a elaboração de um projeto para a reforma da praça. As obras iniciaram-se em 2009, e a "nova" praça das Corujas foi entregue em 20 de fevereiro de 2010, contando com a presença do então prefeito Gilberto Kassab:

A praça Dolores Ibárruri foi revitalizada nos anos de 2009 e 2010. Com projeto dos arquitetos Paulo Pellegrino e Elza Niero e estudo hidrológico realizado por professores do Departamento de Hidráulica da Poli-USP, a praça foi pensada para receber uma série de intervenções da chamada infraestrutura verde a fim proporcionar a retenção e infiltração local de águas pluviais e o retardamento do escoamento superficial. Trata-se de uma estratégia para evitar sobrecargas nas galerias de águas pluviais, cada vez mais pressionadas pelo processo de impermeabilização da cidade, mas que não se limita a isso: além de ajudar no controle às enchentes, as tipologias de infraestrutura verde também desempenham outras funções tais como conforto ambiental, suporte à biodiversidade e notadamente a redução da poluição difusa das águas por meio da vegetação. (Oliveira, Soares e Bonzi, 2012, p. 46)

Os diferentes tipos de envolvimento dos cidadãos com a atual praça das Corujas criam maior heterogeneidade de usos e de personagens nesse espaço público, ampliando as "fronteiras abertas", que são aquelas que ensejam "a possibilidade concreta do desenvolvimento humano individual e coletivo por meio da intensidade das trocas e interações sociais", ou seja, o oposto da cidade fractal que nega a heterogeneidade e submete as pessoas à vida entre seus iguais (Rolnik, 2014, p. 77).

\section{Os hortelões urbanos}

0 processo inicial de materialização da Horta das Corujas esteve condicionado ao surgimento, na cidade de São Paulo, da rede denominada "Hortelões Urbanos", no ano de 2011. Este foi um passo fundamental para agrupar um conjunto de entusiastas na temática da agricultura urbana, cujo interesse, inicialmente, 
era discutir a produção de alimentos na cidade, mas que também trazia uma vontade ativista de dar início à prática da agricultura urbana em espaços públicos. Os Hortelões Urbanos foram concebidos pelas jornalistas Tatiana Achcar e Claudia Visoni, que criaram um "grupo público" (de livre acesso) no Facebook para a troca de experiências e informações relacionadas à agricultura urbana de escala doméstica ou comunitária.

Achcar e Visoni chegaram a ministrar pequenos cursos (workshops) sobre questões concernentes à sustentabilidade urbana em São Paulo. Um desses encontros temáticos, realizado em fevereiro de 2011, foi sobre agricultura urbana. Em sua passagem por San Francisco (EUA), Achcar deparou-se com o fato de que as hortas urbanas recebiam atenção especial do poder público local, que disponibilizava infraestruturas próprias às iniciativas comunitárias. Para ela, o mais importante seria ampliar o debate, em São Paulo, acerca do espaço urbano, o que, inclusive, lhe motivou a batizar sua iniciativa com o termo "hortelão":

Quando surgiu a ideia de criar o grupo, fui em busca de nomes que remetessem a horta e não a sítio ou a agricultura. Acho horta singelo. E então encontrei essa palavra da língua portuguesa, mas usada em Portugal. Ela soou tão bem, e nos acolheu tão bem... e hoje somos tantos. (Achcar, 2015)

Quanto ao uso da rede social Facebook como instrumento de organização da ação coletiva, segundo Castells (2013, p. 171, grifo do autor):

As redes sociais digitais baseadas na internet e nas plataformas sem fio são ferramentas decisivas para mobilizar, organizar, deliberar, coordenar e decidir. Mas o papel da internet ultrapassa a instrumentalidade: ela cria as condições para uma forma de prática comum que permite a um movimento sem liderança sobreviver, deliberar, coordenar e expandir-se. [...] Além disso, há uma conexão fundamental, mais profunda, entre internet e os movimentos sociais em rede: eles comungam de uma cultura específica, a cultura da autonomia, a matriz cultural básica das sociedades contemporâneas.

Após o surgimento oficial dos Hortelões Urbanos no Facebook, em 26 de julho de 2011, a comunicação entre os engajados no tema tornou-se mais fácil, aproximando interessados sobre a temática tanto da cidade de São Paulo quanto de outras partes do País e do mundo, que, ao fazerem pesquisas sobre "agricultura urbana", "horticultura doméstica", "hortas comunitárias", etc., encontravam esse novo espaço virtual para trocar ideias, conhecimentos e experiências práticas.

Nesse período inicial dos Hortelões Urbanos na internet, alguns de seus membros se organizaram virtualmente para promover encontros presenciais e melhor debater possibilidades e estratégias de ocupação do espaço público, com o objetivo de criar uma horta comunitária. Nessa etapa do engajamento coletivo, Visoni começava a se tornar uma referência para esse tipo de ativismo, agregando simpatizantes e ampliando a rede formada pelos diversos personagens engajados em agricultura urbana.

0 primeiro encontro presencial organizado pela página dos Hortelões Urbanos no Facebook aconteceu no dia 16 de maio de 2012, às 20 horas, na padaria Villa Grano, ${ }^{3}$ no bairro da vila Madalena. Um dos desdobramentos desse primeiro encontro não virtual dos 
Hortelões Urbanos foi a criação de grupos de trabalho (GTs), com o propósito de focar em seus objetivos de atuar na cidade e em seus espaços públicos.

Nessas reuniões, em 2012, alguns hortelões, já inspirados pelos movimentos de guerrilla gardening de outras partes do mundo - que ocupam espaços públicos ou privados, na cidade, sem prévia autorização, para fins agrícolas ou de jardinagem -, decidiram, enfim, partir para a ação. A materialização da primeira horta comunitária de caráter ativista da cidade de São Paulo (Muda-SP, 2015), consequente à articulação inicial dos Hortelões Urbanos, estabeleceu-se na praça das Corujas: a Horta das Corujas.

A partir da relação horizontal (não hierarquizada) entre seus membros, os Hortelões Urbanos, inicialmente, teriam a pretensão de se constituir enquanto movimento ativista em prol da produção de alimentos no espaço urbano (sobretudo no modelo de hortas comunitárias), preenchendo uma lacuna que havia, na cidade de São Paulo, nesse tipo de atuação e mobilização política. Em 2012, o grupo chegou a escrever um manifesto que serviria para identificar a ideologia de seus integrantes e expor suas posições publicamente (Cidades Comestíveis, 2015).

Entretanto, com a rápida adesão de pessoas ao grupo pelo Facebook, a ideia de que os Hortelões Urbanos possuíssem uma unidade político-ideológica foi se perdendo. A grande parte desses novos "conectados" não tinha conhecimento da origem do grupo, não conhecia ou não compartilhava, necessariamente, daquele conteúdo apresentado pelo manifesto, tampouco poderia ser representada politicamente enquanto parte de um "movimento".
Dessa forma, os Hortelões Urbanos acabaram se configurando como rede de troca de informações on-line sobre a produção de alimentos na cidade, sem possuir uma organização capaz de lhe conferir uma identidade e unidade política. A expressão "hortelão urbano" é genericamente empregada para qualificar uma modalidade de agricultor urbano, mais precisamente, para identificar o cidadão que não é agricultor de profissão (nem que exerça essa atividade como sua principal fonte de renda), ativista ou não, mas que usa o espaço urbano para produzir alimentos (seja o espaço público ou privado, seja em escala doméstica ou comunitária).

A página dos Hortelões Urbanos, no Facebook, é bastante heterogênea. Frequentada por pessoas de diversas partes do Brasil e do mundo, com as mais variadas idades e com um perfil ideológico e socioeconômico predominante bastante difícil de identificar, as discussões ali presentes são basicamente sobre o manejo e os cuidados necessários no cultivo doméstico das mais variadas espécies de plantas (alimentícias ou não). A grande parte das postagens não apresenta conteúdo politizado nem pretende criar discussões de caráter político-ideológico, porém, esporadicamente, há publicações informando sobre algum ato ou manifestação, pedindo ajuda na divulgação ou coleta de assinaturas para um abaixo-assinado ou petição, entre outros casos particulares.

Os membros dos Hortelões Urbanos, no Facebook, geralmente solicitam sementes e mudas; tiram as mais variadas dúvidas (por exemplo, como realizar a poda corretamente; que tipo de instrumento ou material usar em uma situação específica; se uma determinada planta é comestível ou não; qual é o nome de alguma espécie vegetal, etc.); pedem ajuda no 
manejo de suas plantas ou questionam os demais membros do grupo sobre como controlar algum tipo de praga; além de postar fotografias que ilustrem os casos em questão ou para mostrar o vigor e a beleza cênica de sua produção doméstica (fotos de flores, legumes, folhagens, raízes e tubérculos que foram colhidos, etc.). Há, também, convites para mutirões de hortas comunitárias e demais atividades coletivas que acontecem nas cidades.

Uma das grandes problemáticas concernentes ao que se transformou os Hortelões Urbanos é justamente sua participação e o envolvimento político nas questões socioambientais urbanas nestes últimos anos. Postagens na página do grupo revelam que esta foi uma das extensas discussões que aconteceram no Facebook. Usuários mostram-se contrários a assinarem petições e demais documentos oficiais (sobretudo aqueles direcionados ao poder público) utilizando o nome "Hortelões Urbanos", com a justificativa de que o grupo se tornou apenas um fórum de discussão ou uma rede para a troca de informações e divulgação de ações, e não um movimento que possa responder por todos que fazem parte dele no Facebook. A saída encontrada é usar a rede social da internet para divulgar os documentos e quem tiver interesse assina individualmente, ou, ainda, há grupos ativistas que assinam como sendo um coletivo de "agricultores urbanos" ou de "hortelões urbanos", com a grafia em minúsculas, para fazer a diferença do grupo do Facebook "Hortelões Urbanos" (nome próprio).

A grandiosidade da rede na internet e a expressividade ativista que alguns de seus membros conquistaram desde que o grupo surgiu já não são mais fatos insignificantes nas esferas de decisão política na capital paulista, pelo menos ao que se refere à agricultura urbana e à ressignificação do espaço público. Em 2015, à época da aprovação da lei n. 16.212, que dispõe sobre a gestão participativa das praças do município de São Paulo, o ex-vereador Nabil Bonduki, autor do projeto, afirmou que

[...] as iniciativas dos paulistanos para a ocupação cidadã das praças têm aumentado. Movimentos e coletivos com os Hortelões Urbanos, Movimento Boa Praça, Ocupe e Abrace Praça da Nascente Iquiririm, Rios e Ruas, entre outros, vêm trazendo vida às praças paulistanas e contribuindo para requalificação desses espaços públicos, trazendo de volta um conceito básico da cidadania que andava meio esquecido: o significado da palavra público - que quer dizer de todos, e não de ninguém. (Bonduki, 2015, s.p.; grifo nosso)

Porém, como afirma Freeman (1970, s.p.):

Quanto mais "inestruturado" um movimento é, menos controle ele tem sobre as direções na qual se desenvolve e sobre as ações políticas na qual se engaja. Isso não significa que suas ideias não vão se espalhar. Dado um certo grau de interesse dos meios de comunicação e condições sociais favoráveis, as ideias poderão ser difundidas amplamente. Mas o fato de as ideias serem difundidas não implica que serão implementadas; significa apenas que serão discutidas. Na medida em que podem ser aplicadas individualmente, elas podem ser realizadas, mas na medida em que requerem poder político coordenado para ser implementadas, elas não 0 serão. 
Sobre a dificuldade organizacional, em ter apenas a rede social como instrumento de articulação, Castells $(2003$, p. 7$)$ afirma que

apesar de suas vantagens em termos de flexibilidade, as redes tiveram tradicionalmente de lidar com um grande problema, em contraste com hierarquias centralizadas. Elas têm tido considerável dificuldade em coordenar funções, em concentrar recursos em metas específicas e em realizar uma dada tarefa dependendo do tamanho e da complexidade da rede.

Apesar do dilema identitário, a rede dos Hortelões Urbanos foi decisiva para alavancar a materialização de hortas comunitárias na cidade de São Paulo, além de propiciar debates sobre a produção hortícola no espaço urbano por meio das redes sociais. No Facebook, as pessoas interagem, mesmo que apenas na esfera virtual, e também podem ter acesso a informações sobre as ações ativistas referentes à agricultura urbana. Existem outros grupos na internet que também poderiam desempenhar essa função, entretanto os Hortelões Urbanos, por terem sido os pioneiros, tornaram-se uma referência sobre a temática da produção de alimentos na cidade.

\section{A materialização da Horta das Corujas}

A sinergia entre duas mulheres foi fundamental para a instalação da Horta das Corujas em 2012: Claudia Visoni, criadora da rede dos Hortelões Urbanos e que já vinha com a ideia de cultivar para além de seu próprio quintal; e Madalena Buzzo, vizinha à praça das Corujas desde 2008, e então conselheira do Conselho do Meio Ambiente, Desenvolvimento Sustentável e Cultura da Paz de Pinheiros (Cades-PI).

Ao frequentar reuniões ${ }^{4}$ do Cades-PI em 2011, Visoni conheceu Buzzo e conseguiu uma importante aliada familiarizada com os expedientes do poder público local. A aproximação entre a prática ativista e a efetiva participação em conselhos municipais (que possibilitava o diálogo direto com o poder local) acabaria pautando os passos para a materialização de uma horta comunitária em espaço público. Segundo Souza (2000, p. 257), algum apoio institucional é bem-visto como garantia material de manutenção de uma iniciativa, além de funcionar como um instrumento de fortalecimento político contra possíveis opositores à sua existência: "Isolados, os empreendimentos comunitários são muito frágeis. Esses grupos carecem ainda do apoio institucional sistemático de agências externas e também do trabalho voluntário de simpatizantes [...]".

Buzzo e Visoni conseguiram juntar forças para traçar as estratégias necessárias a fim de criar uma horta, especificamente, na praça das Corujas. Apesar das investigações feitas sobre as primeiras articulações dos membros dos Hortelões Urbanos, no Facebook, para que houvesse reuniões presenciais, demostrarem maior concentração de simpatizantes da causa que viviam mais próximos da vila Madalena, o cerne da questão locacional refere-se à sinergia de atuações ativistas distintas que, somadas, viabilizaram a empreitada naquela praça: a frente conduzida por Visoni, que a princípio estaria disposta a partir para a ocupação do espaço público sem prévia autorização para materializar uma nova experiência de agricultura urbana de base comunitária, encontrou garantias 
de sucesso e perenidade da ação em outra modalidade de ativismo, aquela que visa a ocupar os conselhos participativos municipais a fim de dar voz às demandas locais em diálogo direto com o poder público.

Muito embora naquele momento não estivesse, na agenda programática de Buzzo, levantar a bandeira, junto ao Cades-PI, para se materializar uma horta comunitária na praça das Corujas, e que a ideia da ação tivesse chegado por intermédio de Visoni, esse encontro de diferentes métodos e expressões ativistas sinaliza que "há no urbano uma multiplicidade de práticas prestes a transbordar de possibilidades alternativas", mediante as quais as pessoas se empoderam "para criar novos espaços comuns de socialização e ação política" (Harvey, 2014, p. 22).

Para angariar mais hortelões dispostos a partir para a prática, foram feitas chamadas pelo Facebook e por meio de cartazes em padarias e lugares estratégicos do bairro, divulgando uma primeira reunião de pessoas interessadas em ser voluntárias em uma horta comunitária. No dia 14 de julho de 2012, na praça das Corujas, foi feita uma primeira reunião de interessados em participarem do processo de criação da horta.

Nessa ocasião, fez-se uma ata para registrar os principais pontos ali discutidos entre os hortelões, e contabilizou-se a presença de 23 pessoas. 0 documento também comprovaria, à subprefeitura de Pinheiros, que cidadãos estavam prontos para iniciar o processo de materialização da primeira horta comunitária em praça pública. Salientou-se que se trataria de um "projeto experimental", capaz de inspirar sua replicação por outras regiões da cidade. Outras questões também foram levantadas, tais como: buscar parcerias com as escolas da vizinhança (públicas e privadas); iniciar as atividades por meio da adubação verde (quando se plantam leguminosas, que enriquecem o solo com nitrogênio e Ihe conferem maior fertilidade); usar a horta como ponto de convivência comunitária e aprendizado socioambiental, cuja primeira oficina seria sobre compostagem, para incentivar essa prática na escala doméstica.

\section{A territorialidade da Horta das Corujas na praça Dolores Ibárruri}

A área ocupada pela horta dentro da praça foi definida, quanto à sua localização e dimensão, levando-se em conta um conjunto de fatores. Primeiramente, devem-se assinalar as características morfológicas e hidrográficas do terreno local. A praça das Corujas, em sua totalidade, ocupa uma íngreme vertente entre as altas colinas do bairro da vila Beatriz (cujos topos se estendem até o espigão central, onde estão, a noroeste, as ruas Heitor Penteado e Cerro Corá) e o talvegue do córrego das Corujas. A variação altimétrica entre a parte mais alta da praça - de onde se tem um amplo mirante do bairro da vila Madalena - e a área que margeia o córrego das Corujas é de aproximadamente 18 metros. A porção territorial que limita os bairros da vila Madalena, da vila Beatriz e do Alto de Pinheiros, que se estende da vertente leste da rua Heitor Penteado - onde se encontra a nascente do córrego das Corujas - até a baixada do córrego das Corujas, junto à "parte baixa" da praça, pode apresentar desníveis 
de 70 a 80 metros, com declividades acima de 50\% (Schutzer, 2012).

Por isso, a oralidade cotidiana registra as designações "parte alta" e "parte baixa" para referir-se aos diferentes níveis topográficos bastante evidentes (e conservados pelo projeto paisagístico) na praça. A horta, por sua vez, foi instalada na "parte baixa" da praça, numa porção anteriormente recoberta por gramíneas, entre o passeio público - facilitando 0 acesso dos transeuntes e dos voluntários e a íngreme vertente que leva à "parte alta" da praça. Porém, a Horta das Corujas acabou ocupando uma porção que se estende, aproximadamente, até a cota equivalente à média aritmética da encosta. Por isso, as expressões "parte baixa" e "parte alta" podem-se referir tanto à praça em sua totalidade, como também são empregadas, especificamente, pelos frequentadores da horta, já que esta possui uma "parte baixa" (próxima do portão) e uma "parte alta" (localizada na vertente em si), que foram ligadas por degraus confeccionados em determinados mutirões.

Essa característica topográfica da horta permitiu que os primeiros voluntários, que logo no início foram atrás de uma fonte de água permanente dentro do conjunto territorial reservado a ela, identificassem uma área de nascente. Os depoimentos coletados apontam que essa área da praça também era menos utilizada por seus frequentadores porque era onde se dizia ser um "charco". Antes da reforma da praça (2008-2010), essa área costumava alagar nos períodos de chuva, destacadamente durante o verão (Prefeitura de São Paulo, 2016).

Para além da geomorfologia local, estendeu-se o processo político de ocupação de uma parcela da praça das Corujas. Logo que Visoni trouxe a ideia de se criar uma horta comunitária em uma praça pública, Buzzo tratou de levar a novidade, em maio de 2012, ao então subprefeito de Pinheiros. Não existia legislação que proibisse nem que permitisse a existência de uma horta em praça pública. A legitimação do poder público era uma questão fundamental para Buzzo, assim como para outros voluntários, pois garantiria que não houvesse, porventura, queixas e acusações de que os hortelões estariam privatizando ou ocupando arbitrariamente o espaço público.

Apesar de o artigo 114 da Lei Orgânica do Município de São Paulo possibilitar o uso dos bens públicos municipais - "Os bens municipais poderão ser utilizados por terceiros, mediante concessão, permissão, autorização e locação social, conforme o caso e o interesse público ou social, devidamente justificado, o exigir" (ibid.), - em 2012, porém, não existia lei específica para a instalação de hortas urbanas em praças públicas.

A atuação de Buzzo para que houvesse o cercamento da área da horta, dentro da praça das Corujas, com mão de obra cedida pela subprefeitura de Pinheiros - bem como os registros fotográficos desse procedimento - acabou por legitimar a ação ativista. 0 cercamento simbolizou, especialmente perante os moradores do entorno, que houve o diálogo prévio e a aprovação do poder público para a materialização da Horta das Corujas.

A cerca de um metro de altura que demarca a horta também simboliza a expressão material de suas fronteiras no conjunto territorial da praça das Corujas: os $800 \mathrm{~m}^{2}$ de horta são imediatamente identificáveis pelos transeuntes e frequentadores assíduos da praça. "Afinal de contas, o espaço é demarcado 
quando alguém estabelece fronteiras, separando um pedaço de chão do outro" (Damatta, 1997, p. 32). Portanto, com a cerca, o território da horta torna-se visualmente evidente. Por sua vez, apesar de a cerca demarcar com precisão a porção territorial destinada às atividades locais de agricultura urbana, por se tratar de uma área em praça pública, todos têm livre acesso à horta em qualquer horário e dia da semana. Na prática, a cerca baixa (que qualquer pessoa adulta seria capaz de pular ou mesmo de derrubá-la sem grandes dificuldades) não promove isolamento ou segregação socioespacial, é apenas uma barreira protetora para preservar os canteiros da entrada de animais ou demais pisoteios acidentais, e os dois portões que possui encontram-se, permanentemente, apenas encostados.

A inauguração "oficial" da Horta das Corujas também teria sido mais uma estratégia bem-articulada, dessa vez por Visoni. Apesar de a primeira reunião entre os futuros voluntários ter ocorrido em 14 de julho de 2012 e, de acordo com depoimentos e registros fotográficos coletados, eles já terem iniciado os trabalhos no local onde se instalaria a horta, a cerimônia de inauguração ficou para após a finalização do cercamento da área pela subprefeitura de Pinheiros. Visoni, que é jornalista e tem bom relacionamento com os meios de comunicação, enviou uma sugestão de pauta para o jornal $O$ Estado de S.Paulo.

Enquanto Buzzo providenciava legitimidade junto ao poder público e à vizinhança, Visoni tratou de publicitar a iniciativa, expandindo o alcance de sua luta ativista. Em 29 de setembro de 2012, foi feita uma festa de inauguração, na qual compareceram moradores locais, ativistas da causa socioambiental, imprensa e demais simpatizantes e curiosos. A oposição da vizinhança foi de caráter pontual e durante o período nascedouro da horta, sem grandes repercussões e desentendimentos. Entretanto, existiu o questionamento quanto à possível privatização do espaço público.

Ladner (2011, p. 190; tradução nossa) afirma que hortas e jardins comunitários realmente costumam enfrentar a crítica de que promovem apropriação do espaço público para uso privado, a fim de satisfazer a vontade de um grupo específico de pessoas que se intitulam "hortelões". Entretanto, o autor mencionado enfatiza que esses mesmos hortelões estão dando manutenção para uma porção do parque ou da praça e que, portanto, conservam o espaço público; produzem uma "paisagem criativa"; e permitem um olhar interativo dos visitantes, estimulando sua entrada na horta ou no jardim, sua contemplação e demais "bisbilhotices": "Os benefícios dessas hortas são tão diversos e óbvios, que essas rusgas se tornarão irrelevantes ao longo do tempo, especialmente se a horta tiver uma coalizão ampla o suficiente de defensores".

Um posicionamento contrário à Horta das Corujas, que apareceu em depoimentos de dois moradores do entorno, levanta a crítica de que as pessoas que a materializaram acham que a praça é a "casa" delas. Nessa acepção, dois sentidos de "casa" podem ser confundidos, uma vez que: "A casa define tanto um espaço íntimo e privativo de uma pessoa (por exemplo: seu quarto de dormir) quanto um espaço máximo e absolutamente público, como ocorre quando nos referimos ao Brasil como nossa casa" (Damatta, 1997, p. 16; grifo do autor). Nessa acepção, certamente, os críticos à Horta das Corujas utilizam-se do primeiro 
sentido de "casa" para introduzirem a ideia de que parte da Praça das Corujas se tornou uma extensão do quintal dos hortelões, conjecturando, ainda, a possível privatização do espaço público.

Além disso, uma das principais características que clarificam o papel agregador das hortas comunitárias, refutando práticas e princípios segregadores ou mesmo que objetivassem a privatização do espaço público, é a necessidade de compartilhamento, entre as pessoas envolvidas, do que há nelas. Ferramentas, solo, alimentos, água, sementes, trabalho, composto, etc. são necessariamente compartilhados entre os hortelões: sem um grupo de pessoas que esteja disposto a socializar e trabalhar de forma solidária, a materialização de uma horta comunitária não se torna possível.

0 espaço público, quando receptor de iniciativas hortícolas dessa natureza, também se apresenta mais heterogêneo, na medida em que passa a abrigar, em si, diferentes tipos de usos. A praça das Corujas, por exemplo, ganhou mais um equipamento do qual seus usuários podem tirar proveito. A horta não é a única opção de lazer no local, pois ela ocupa uma porção diminuta da área total da praça e não foi alojada sobre ou em detrimento de outro equipamento urbano, mas, sim, onde antes havia uma extensão de gramado subutilizado e algumas árvores (que foram preservadas).

Finalmente, essa expressão de agricultura urbana apresentou conquistas em matéria de lei municipal e vem a encerrar as possíveis confusões sobre a privatização do espaço público por meio de ações cidadãs dessa natureza. A participação de ativistas defensores da causa em audiências públicas e as suas ações criadoras de hortas comunitárias, com destaque ao pioneirismo e à relevância socioespacial conquistada pela Horta das Corujas, foram fundamentais para esse reconhecimento por parte do Poder Legislativo.

Em 2013, o ex-vereador Nabil Bonduki apresentou o substitutivo ao projeto de lei n. 289/2013, que dispõe sobre a gestão participativa das praças do município de São Paulo e estabelece seus objetivos, princípios e instrumentos. Dentre os equipamentos e o mobiliário urbano que as praças poderão ter, as hortas comunitárias orgânicas de caráter educativo foram incluídas no artigo 15:

Art. 15. [...] as praças poderão ter equipamentos e mobiliário urbano, tais como: I) lixeiras para coleta seletiva; II) parque infantil; III) equipamentos para exercícios físicos; IV) bancos; V) áreas de estar com mesas para jogos e piqueniques; $\mathrm{VI}$ ) ponto para ligação de água e luz; VII) estacionamento para bicicletas; VIII) horta comunitária orgânica, de caráter educativo; IX) painéis informativos; $X$ ) quiosques para piquenique; XI) palco para manifestações artísticas; XII) guaritas. (Câmara Municipal de São Paulo, 2016; grifo nosso)

Segundo Bonduki, ${ }^{5}$ os hortelões urbanos foram importantes para a inclusão das hortas, ressaltando: "Em todos os projetos de lei que elaboro, busco conversar com os principais atores envolvidos no tema. Para isso, fizemos várias reuniões e audiências públicas, com grande envolvimento de diferentes usuários das praças".

Os artigos 18, 19 e 20 do referido projeto de lei também citam as hortas comunitárias e fazem referência à possível presença de composteiras junto a elas - a fim de permitir a obtenção de composto orgânico in loco -, além de destacar a utilização dos 
princípios da permacultura como norteadores de sua manutenção:

Art. 18. As propostas de instalação de hortas comunitárias orgânicas de caráter educativo nas praças deverão ser encaminhadas para as respectivas subprefeituras, mediante solicitação contendo, no mínimo, a localização, as dimensões e a indicação dos responsáveis pela manutenção. $\S 1^{\circ} \mathrm{A}$ Unidade de Áreas Verdes da subprefeitura expedirá manifestação considerando as condições de solo, irrigação, insolação, topografia e entorno, ouvindo o comitê de usuários quando houver.

$\S 2^{\circ}$ Havendo autorização para a instalação da horta, a subprefeitura apoiará a implantação dentro de suas possibilidades, em parceria com a Supervisão de Abastecimento da Secretaria de Coordenação das Subprefeituras.

Art. 19. As praças que sediarem hortas comunitárias orgânicas poderão ter composteiras, construídas e mantidas segundo os princípios da permacultura urbana, pelos responsáveis pela respectiva horta.

$\S 1^{\circ} \mathrm{A}$ instalação de composteiras deverá ser autorizada pela respectiva subprefeitura, ouvido o comitê de usuários quando houver.

$\S 2^{\circ}$ Caberá aos responsáveis pela horta informar os frequentadores da praça sobre o correto manejo das composteiras, podendo para tanto desenvolver campanhas e ações educativas na praça e entorno, envolvendo o comitê de usuários, quando houver.

Art. 20. A Secretaria de Coordenação das Subprefeituras deverá elaborar, com participação da sociedade civil, uma cartilha para a implantação, manutenção e reforma de praças, abordando questões como acessibilidade, porcentagem de área permeável, instalação de equipamentos e mobiliário urbano, orientação para hortas comunitárias orgânicas, entre outras, informando a quem cabe a responsabilidade pelos serviços públicos e estabelecendo os parâmetros para os equipamentos e serviços dispostos nos artigos 14, 15, 16, 17, 18 e 19 desta Lei. (Ibid.; grifo nosso)

A agricultura urbana como possível atividade a integrar as praças públicas na cidade de São Paulo não apresentaria, de acordo com a referida lei, fins de abastecimento alimentar, nem de geração de renda. A produção de alimentos orgânicos, nesse modelo de horta urbana, seria mais um dos equipamentos públicos disponíveis para: usufruto comunitário, finalidades educativas (educação socioambiental) e integração social nas praças.

0 projeto de lei supracitado foi aprovado pelos vereadores do município de São Paulo em maio de 2015. No dia 10 de junho de 2015, 0 então prefeito, Fernando Haddad, promulgou a lei sobre a gestão participativa das praças no município (lei $n .16 .212$ ), fato comemorado pelos ativistas, que passaram a contar com esse amparo jurídico para dar alguma garantia de sobrevivência às hortas comunitárias localizadas em praças públicas e viram, também, parte de suas lutas legitimadas pelo poder público.

\section{Os mutirões}

"Mutirão" é uma palavra bastante frequente no linguajar dos envolvidos com a Horta das Corujas, nas conversas pela internet e entre hortelões em geral. Carneiro (2008, pp. 42-43) ensina que a cooperação vicinal é uma tradição antiga e existente em diferentes sociedades, e "à forma brasileira de auxílio mútuo entre vizinhos dá-se geralmente o nome de 'mutirão' [...]", palavra de origem indígena que foi 
aportuguesada. Segundo o referido autor, ele já foi de "grande importância para a economia de agricultores e sitiantes", nos quais "os vizinhos comparecem, com suas ferramentas e utensílios [...]".

Os mutirões acabam sendo a forma mais eficaz de estimular o trabalho coletivo e de atrair voluntários para as hortas comunitárias, tornando-se um "programa" e uma "diversão" para os fins de semana, quando hortelões levam amigos ou familiares para os encontros de trabalho coletivo. Porém, "a despeito dos aspectos lúdicos que o transformam em festa, 0 mutirão é essencialmente uma ocasião de trabalho" (ibid., p. 43). Esses momentos, ao deixarem a horta mais povoada, ativam a noção de solidariedade, de cooperação e de interação comunitária (Singer, 2002).

As pessoas que costumam aparecer nos mutirões programados não são apenas aquelas mais frequentes no convívio cotidiano da Horta das Corujas. Muitas delas aproveitam para visitar o local pela primeira vez ou para se integrarem e conhecerem o trabalho dos hortelões. Como os anúncios são feitos pelo Facebook, muitos internautas tomam conhecimento do "evento" e se juntam à empreitada. Os mutirões também são encarados como a atividade física do fim de semana. Segundo Reynolds (2009, pp. 29-30, tradução nossa), a horticultura "é um bom exercício", "uma alternativa barata às academias e mais segura do que os esportes radicais", e cujos resultados do esforço pessoal não aparecem "apenas no espelho, mas também quando se avalia a paisagem".

Os mutirões tendem a ser eficientes em sua finalidade, ou seja, a atividade escolhida como sendo a principal daquele dia é satisfatoriamente realizada pelos voluntários. No entanto, não adianta cobrar muita disciplina, exigir muito planejamento e ter demasiadas expectativas no que se refere ao cumprimento de horários e de tarefas, pois estas se realizam de maneira mais espontânea e conforme a possibilidade e disposição física (e emocional) de cada indivíduo (ibid.).

\section{A estética}

Hortas urbanas são um importante instrumento pedagógico e político no que se refere à transformação da paisagem local por intermédio da permacultura, em que há integração entre diferentes espécies sem a tradicional monotonia de formas e espécies propostas pela "agricultura tradicional":

A permacultura é, antes de tudo, uma ética para cuidar da terra e dos seres vivos. Nesse sistema, ela copia a natureza, já que ela repousa sobre a interação dos elementos que estão presentes (água, árvores, legumes, animais...). As plantas são reagrupadas em função de suas sinergias naturais: algumas retêm água, outras geram substâncias naturalmente não nocivas ou nutrem os solos. (Manier, 2012, p. 169; tradução nossa)

A grande parte dos voluntários entrevistados, mesmo sem fazer associações à permacultura, compartilha de alguns de seus princípios, a exemplo de que a horta seja um instrumento de cooperação entre as pessoas e de transição para outro tipo de relação com os ciclos da natureza e com a paisagem urbana, "baseado em fatores mais ecológicos do que econômicos" (Mollison e Holmgren, 1983, p. 112). 
Contrariamente à agricultura industrial, que faz as plantas crescerem sobre os substratos mortos, enriquecidos quimicamente, a permacultura repousa [...] sobre a utilização de solos vivos, enriquecidos por compostos orgânicos (folhas, dejetos animais, cogumelos...) e os agentes naturais (insetos polinizadores, fauna do subsolo...). Ela recria o processo de regeneração dos ecossistemas e, sobre esses solos vivos, [...] deixa a natureza trabaIhar sozinha. (Manier, 2012, p. 170; tradução nossa)

Tracey (2007) salienta que a aparência pode ser um mecanismo eficiente para impressionar os olhos alheios nas ações de horticultura urbana. Interferir positivamente na paisagem é um mecanismo de angariar simpatizantes para a causa: a beleza cênica ajuda a conferir uma imagem positiva de revalorização do espaço público.

Dentre as novidades da horticultura urbana, elenca-se a promoção das Plantas Alimentícias Não Convencionais (Panc):

Panc nada mais é do que um acrônimo para tentar contemplar as "Plantas Alimentícias Não Convencionais", ou seja, plantas que possuem uma ou mais das categorias de uso alimentício [...] mesmo que não sejam comuns, não sejam corriqueiras, não sejam do dia a dia da grande maioria da população de uma região, de um país ou mesmo do planeta, já que temos atualmente uma alimentação básica muito homogênea, monótona e globalizada. [...] Este nome foi cunhado e começou a ser usado e divulgado em 2008 [...]. 0 conceito representado pelo acrônimo Panc é mais amplo, flexível [...], contemplando todas as plantas que têm uma ou mais partes ou porções que pode $(\mathrm{m})$ ser consumida(s) na alimentação humana, sendo elas exóticas, nativas, silvestres, espontâneas ou cultivadas. [...] Naturalmente que esta categorização como Panc não é perfeita nem matemática. [...] Mas, na média, tudo que a grande maioria das pessoas já ouviu falar, conhece ou pelo menos sabe dizer o nome e dispensa ter de mostrar fotos ou plantas, é convencional. (Kinupp e Lorenzi, 2015, pp. 14-16)

Muitas das Panc são espontâneas, por isso, o que aparentemente pode ser considerado "mato", e que deveria ser retirado de uma horta, acaba sendo mantido junto às espécies popularmente conhecidas, e o seu consumo, estimulado. Kinupp e Lorenzi (ibid., p. 13) destacam que muitas Pancs são consideradas popularmente como "daninhas", "matos", "invasoras", "infestantes", "inços" e "nocivas", por aparecerem entre "plantas cultivadas ou em locais onde as pessoas 'acham' que não podem ou não devem ocorrer", além de serem desconhecidas por grande parte da população e do poder público. Atualmente, no entanto, já existem canais informativos (sobretudo na internet) que ensinam receitas e propriedades para estimular o seu uso.

Nesse sentido, o aprendizado coletivo sobre outra "noção" de horta, que incorpore os preceitos da permacultura, da agroecologia e que estimule a produção orgânica e a maior biodiversidade local, acaba por se enquadrar na função educativa das hortas comunitárias urbanas, que também é prevista pela lei n. 16.212/2015 (sobre a gestão participava das praças). Todos os usuários da praça das Corujas que foram entrevistados por esta pesquisa, sejam os hortelões ou aqueles contrários à existência da horta, assumiram em seu discurso que a horta contribui, de alguma 
maneira, para finalidades educativas. Ter a possibilidade de aprender a identificar, manejar e consumir alimentos não convencionais também seria um aspecto da diversidade proporcionado por essa expressão de agricultura urbana. Mesmo que o objetivo principal do cultivo em hortas comunitárias não sejam a segurança alimentar e a subsistência, essa expressão de agricultura urbana mobiliza a sociedade para refletir sobre a sua capacidade de autoprodução (Nagib, 2018).

\section{Consumir é seguro?}

Uma das principais preocupações referentes à produção de alimentos em espaços públicos intraurbanos concerne à sua real segurança sanitária, que diz respeito aos possíveis riscos a que os seus consumidores estariam expostos. O compartilhamento do ar, da água e do solo em áreas densamente povoadas eleva o grau de atenção e preocupação dos diferentes setores da sociedade. Existem, ainda, preocupações quanto à reprodução de mosquitos e demais transmissores de doenças (vetores), especialmente em São Paulo - e no Brasil de maneira geral - com a elevada incidência de casos de dengue, chikungunya e zika, moléstias virais transmitidas pelo mosquito Aedes aegypti.

No entanto, associar as hortas urbanas ao aumento dos casos de doenças e contaminações, ou tê-las como sinônimo de ambientes insalubres, muitas vezes relaciona-se à falta de informação e pode potencializar preconceitos ou disseminar falsos prognósticos, já que as reais causas dos problemas de saúde ou a exposição a eles geralmente se associam às precariedades infraestruturais, tais como a ausência de saneamento básico e demais cuidados com a qualidade e o manejo dos recursos naturais (Smit, Nasr e Ratta, 2001).

Três fontes de contaminação foram levantadas para investigar a situação da Horta das Corujas: poluição do ar, da água e do solo. Em relação à poluição atmosférica, revela-se pertinente a preocupação quanto à acumulação de metais pesados nos vegetais cultivados, já que o intenso tráfego veicular e outras atividades (a exemplo da industrialização) liberam grandes quantidades de metais pesados no ambiente urbano, podendo acumular-se nas espécies que serão ingeridas pelos cidadãos. Nesse sentido, as barreiras físicas são mecanismos eficientes para a proteção dos poluentes que atingiriam diretamente as hortas, dentre eles, muros e demais estruturas, e a vegetação, tais como árvores ou trepadeiras que façam o cercamento das hortas urbanas (Hoffen e Säumel, 2014).

Amato-Lourenço (2018) desenvolveu pesquisa acerca da concentração de metais pesados provenientes de deposições atmosféricas nos vegetais em hortas comunitárias da cidade de São Paulo. Conforme o autor, os riscos na capital paulista estariam associados, destacadamente, à poluição do ar pelo tráfego veicular, uma vez que a frota circulante de caminhões e ônibus é muito grande dentro da cidade. Sua pesquisa selecionou dois vegetais que tendem a acumular elementos contaminantes atmosféricos e que estão presentes em grande parte das hortas comunitárias: a couve (que também costuma ser consumida crua pelos cidadãos) e o espinafre.

Especificamente sobre a Horta das Corujas, há uma característica distinta das demais hortas de São Paulo: a grande presença 
de árvores ao seu redor. Localizada no interior da praça Dolores Ibárruri, as espécies arbóreas funcionam como obstáculos verticais para reduzir a incidência de poluentes atmosféricos nos cultivos, pois as partículas chocam-se nos troncos e nas folhas das árvores e diminuem sua concentração nas hortaliças, além de que a horta não está situada nas proximidades de grandes avenidas, em que haveria maior densidade de veículos.

Segundo Amato-Lourenço (ibid.), quando se compara ao que é adquirido nos supermercados, os valores de acúmulo de metais pesados nas hortaliças com até 30 dias de exposição foram bem baixos nas amostras da Horta das Corujas (a pesquisa não detectou nenhuma acumulação do que poderia apresentar risco à saúde). De maneira geral, poder-se-ia dar preferência, na escolha do que será cultivado em hortas urbanas, às plantas de ciclo rápido (que são colhidas em até 30 dias); outra opção seria cultivar o que se consome em menor quantidade absoluta (temperos, por exemplo).

Ressalta-se que as informações levantadas por Amato-Lourenço (ibid.) são referentes à couve e ao espinafre, que tendem a acumular mais metais pesados, e que o cenário no qual se fez a coleta de dados é realmente pessimista, pois os estudos foram realizados durante 0 inverno, que é um período crítico em relação à poluição atmosférica por se tratar da estação seca em São Paulo. Salienta-se, ainda, que muitas áreas produtoras de alimentos localizadas fora dos centros urbanos também estão próximas de rodovias, pelas quais há grande número de caminhões circulando, ou de áreas industriais; então, não se pode admitir, sem prévia pesquisa, que cultivos em hortas urbanas apresentam, indiscriminadamente, maior concentração de metais pesados.

Hoffen e Säumel (2014) destacam que, além da importância de ter árvores como proteção (obstáculos verticais) no entorno de hortas urbanas, as hortaliças folhosas tendem a acumular mais metais pesados - vagens, tubérculos e frutas acumulam muito menos metais pesados, mesmo em solo contaminado - e, por isso, elas devem ser cultivadas mais no interior da horta. Portanto, uma disposição territorial mais segura das espécies comestíveis seria: árvores frutíferas fazendo o cercamento da horta; seguidas pelos feijões e vagens; depois viriam os tubérculos; e as demais hortaliças seriam cultivadas no centro da horta.

No que tange à poluição da água na Horta das Corujas, foram realizadas análises junto à Cetesb: primeiramente, realizou-se o teste de coliformes fecais, mediante coleta simples (em que a água a ser analisada pode ser coletada por qualquer pessoa) e posterior encaminhamento à referente companhia estadual. Esse teste foi pago pelos voluntários. E, entre novembro de 2012 e fevereiro de 2013, uma articulação encabeçada por voluntários e ativistas, mediante o Cades-PI e o envio de carta ao então diretor-presidente da Cetesb, foi fundamental para garantir, junto à companhia estadual, um teste completo sobre a qualidade e as características da água presente na Horta das Corujas (coletada na maior e principal cacimba da horta por agente público responsável). As conclusões da Cetesb - emitida em carta e relatório completo aos voluntários solicitantes - asseguraram o uso da água examinada para fins de irrigação de hortaliças e frutas que são consumidas cruas. Apesar da 
boa qualidade para a rega e as demais necessidades da horta, isso não garante que a água das cacimbas seja potável, já que outros fatores se relacionam à garantia da qualidade para consumo humano, tais como frequência de chuvas, mistura com materiais provenientes do solo, etc. Cabe relembrar, ainda, que o córrego das Corujas, que margeia a praça Dolores Ibárruri e recebe as águas do escoamento superficial da praça em dias de chuva, passou pelo Programa Córrego Limpo, o que supostamente assegura que as suas fontes de despejo (que incluem as águas provenientes da horta) não estão contaminadas.

As cacimbas e a área de nascente da Horta das Corujas também já foram alvo de fiscalização pelos agentes de saúde da prefeitura de São Paulo, que fazem o controle dos focos de dengue no município. Em 25 de abril de 2015 e em 5 de março de 2016, os agentes municipais asseguraram que não havia focos de dengue na área da Horta das Corujas, uma vez que as cacimbas possuem peixes, que se alimentam das larvas (trata-se do controle biológico - controle de pragas exercido por organismos vivos - do vetor das doenças virais dengue, chikungunya e zika), e plantas com raízes aquáticas (espécies hidrófilas), que asseguram a qualidade da água para a sobrevivência dos peixes. Em uma cacimba menor, na qual os peixes não sobreviveram após as tentativas dos hortelões em criá-los ali, aconselhou-se que ela ficasse tampada com tela para dificultar o possível acesso de mosquitos. Na horta, também foi instalada placa explicativa junto à maior e principal cacimba.

Por fim, no que se refere à poluição do solo na área em que está localizada a Horta das Corujas, esta já se configurou uma das primeiras preocupações dos voluntários e, inclusive, foi uma das dúvidas que apareceu na primeira reunião marcada na praça em 14 de julho de 2012. Além da informação informal da Secretaria Municipal do Verde e do Meio Ambiente (SVMA) e da Cetesb de que o solo não seria contaminado por metais pesados, a preocupação com a possível presença de fezes animal - seja de animais de estimação que passeiam na praça ou daqueles que foram criados por Felipe Martins no passado - estimulou o plantio inicial em paletes. ${ }^{6}$ Dessa forma, os primeiros cultivos iniciaram-se suspensos ao solo da praça.

Como o solo urbano costuma ser duro e compactado, criar uma camada de solo novo sobre o original da praça, desde a materialização da horta, foi uma alternativa que viabilizou o manejo cotidiano com os plantios realizados. Além de conhecer a origem do solo - com terra comprada em lojas especializadas ou doada por voluntários -, ele era muito mais macio e fácil de manusear. Desde 2013, os paletes e outros suportes suspensos foram abandonados, e o plantio passou a se realizar diretamente no solo: já foram criadas muitas camadas de solo novo sobre o original, o que dificultaria uma possível contaminação proveniente do assoaIho original da praça.

As precauções com fezes animais são, basicamente, a cerca de um metro de altura que faz a proteção da horta e a confiança de que os frequentadores não deixarão que seus animais de estimação entrem na área de cultivo. Em todos os trabalhos de campo realizados, nunca se presenciou, dentro da horta, cachorros, gatos ou qualquer outro animal que pudesse causar risco de contaminação fecal real aos alimentos. 
Houve, ainda, a utilização de pneus, por aproximadamente dois anos e meio. Eles foram usados como suporte de canteiros ou para improvisar escadas entre a "parte baixa" e a "parte alta" da horta. No segundo semestre de 2015, Visoni iniciou, no Facebook, uma campanha pela retirada dos pneus com base em estudos e reportagens sobre os malefícios ambientais e para a saúde humana que eles poderiam causar. Segundo Brown (2007), os materiais contidos na borracha industrial contaminam a água, o solo e podem estar associados a problemas dermatológicos, oftalmológicos e a tipos de câncer. Por isso, não se recomenda o uso de pneus em atividades ligadas à jardinagem, que, segundo o referido autor, ainda possuem elevado teor de zinco - elemento essencial às plantas, mas que, em excesso, torna-se tóxico.

Paralelamente à possível toxidade dos pneus, estes, ao serem aleatoriamente deixados na horta por frequentadores que não os destinam à imediata função (preenchimento com terra para servirem como suporte de canteiro ou como degrau para vencer os desníveis do terreno), podem acumular água em seu interior e se tornarem criadouros de larvas de mosquitos. Após a campanha de Visoni pela retirada dos pneus, a inciativa teve, enfim, adesão maciça dos hortelões.

\section{Conclusão}

A partir do estudo de caso da Horta das Corujas, experiência pioneira na cidade de São Paulo que está completando 7 anos em 2019, conclui-se que a agricultura urbana como ativismo se associa à materialização de uma luta por melhor qualidade de vida no que se refere à heterogeneidade das convivências cotidianas (aproximação entre as pessoas); possui forte característica ambientalista com toda a transversalidade que essa temática pode oferecer (das questões de saúde urbana à educação ambiental, etc.); e trata-se de uma nova vivência e percepção do espaço urbano que exigirão novas leituras políticas dos territórios, ajudando na consolidação do

[...] direito à cidade, [...] [que, por sua vez,] não é apenas um direito condicional de acesso àquilo que já existe, mas sim um direito ativo de fazer a cidade diferente, de formá-la mais de acordo com nossas necessidades coletivas (por assim dizer), definir uma maneira alternativa de simplesmente ser humano. Se nosso mundo urbano foi imaginado e feito, então ele pode ser imaginado e refeito. (Harvey, 2013, p. 33)

0 empenho para trazer a produção de alimentos para o espaço urbano relaciona-se ao desejo democrático de devolver, aos cidadãos, maior controle sobre a sua comida e sobre as suas vidas, de forma a contribuir para: a conservação e a preservação de espaços públicos; a recreação; a oportunidade de socialização e do trabalho comunitário; e o desenvolvimento de atividades educativas (Ladner, 2011).

Em relação ao conjunto da praça das Corujas, concluímos que o seu uso permanente pelos cidadãos e as distintas maneiras de se apropriar de tal espaço público lhe conferem uma singularidade especial, se não para a totalidade da cidade de São Paulo, ao menos para o território da subprefeitura de Pinheiros, no qual se destaca a gama de atividades que, ali, são realizadas (incluindo a horticultura 
comunitária): "sua existência social, isto é, sua existência real, somente lhe é dada pelo fato das relações sociais", uma vez que "o espaço não pode ser estudado como se os objetos materiais que formam a paisagem tivessem uma vida própria, podendo assim explicar-se por si mesmos" (Santos, 2004, pp. 62-105).

0 processo histórico e o método da pesquisa-ação - em que o pesquisador teve a preocupação de compreender e interagir com os membros da situação investigada (Thiollent, 2011), sendo, inclusive, um desses membros ativos do estudo de caso - revelaram a singularidade de um novo tipo de ativismo urbano que floresceu na década de 2010 na capital paulista. A agricultura urbana como ativismo entra na pauta de discussões, lutas e materializações do direito à cidade. $A$ Horta das Corujas já se firmou como laboratório de políticas públicas socioambientais inclusivas para a cidade de São Paulo, cujo exemplo vem sendo replicado em outras iniciativas semelhantes em outros bairros e distritos, além de abrir as possibilidades de uma transformação cultural sobre a relação da sociedade com a natureza no meio urbano e sobre a potencialidade das relações horizontais entre os cidadãos.

\section{[I] https://orcid.org/0000-0002-4558-7218}

Universidade de São Paulo, Faculdade de Filosofia, Letras e Ciências Humanas, Programa de Pós-Graduação em Geografia Humana. São Paulo, SP/Brasil.

guganagib@hotmail.com

\section{Notas}

(1) As fontes consultadas para a elaboração deste e dos dois parágrafos anteriores a este foram: Prefeitura de São Paulo (2016); Diário Popular (1991; 1994); Folha de S.Paulo (1994).

(2) Reportagem intitulada "Sítio das Corujas é reintegrado à Prefeitura", de quarta-feira, 2 de março de 1994, caderno "Cotidiano". Disponível em: <http://www1.folha.uol.com.br/fsp/1994/3/02/ cotidiano/23.html>. Acesso em: 28 fev 2019.

(3) Padaria 24 horas, localizada na rua Wisard, n. 500.

(4) A população do território da subprefeitura de Pinheiros pode acompanhar os trabalhos do Cades-PI. As suas reuniões acontecem mensalmente no auditório da subprefeitura de Pinheiros (avenida das Nações Unidas, n. 7123) e são abertas ao público.

(5) Mensagem recebida por guganagib@uol.com.br em 8 dez. 2015. 
(6) Espécie de estrado (estrutura plana, em geral de madeira, que se assemelha a um palanque baixo) usado para empilhar, manusear e transportar cargas (Houaiss, 2009). É muito utilizado para o cultivo de hortaliças no espaço urbano, tendo em vista que, preenchido com terra e composto, torna-se canteiro ligeiramente suspenso e também evita o contato direto com o solo local.

\section{Referências}

ACHCAR, T. (2015). Mensagem publicada no grupo "Hortelões Urbanos", na rede social Facebook, em 15 abr.

AMATO-LOURENÇO, L. F. (2018). A influência da poluição atmosférica no conteúdo elementar e de hidrocarbonetos policíclicos aromáticos no cultivo de vegetais folhosos nas hortas urbanas de São Paulo. Tese de Doutorado. São Paulo, Universidade de São Paulo.

ARQUIVO HISTÓRICO DA PREFEITURA DE SÃO PAULO (2019). Dicionário de ruas. São Paulo, Prefeitura de São Paulo. Disponível em: http://www.dicionarioderuas.prefeitura.sp.gov.br. Acesso em: 3 mar 2019.

AZEVEDO, A. (1958). A cidade de São Paulo: estudos de geografia urbana. V. 3 (Aspectos da metrópole paulista). São Paulo, Nacional.

BONDUKI, N. (2015). A gestão participativa das praças: a ocupação dos espaços públicos precisa ser resgatada. Carta Capital. São Paulo. Disponível em: http://www.cartacapital.com.br/sociedade/ cidadania-socioambiental-e-mudanca-cultural-3704.html. Acesso em: 2 jun 2019.

BROWN, D. R. (2007). Artificial turf: exposures to ground-up rubber tires, athletic fields, playgrounds, gardening mulch. EUA, EHHI. Disponível em: http://plasticfieldsfornever.org/turf_report07.pdf. Acesso em: 2 jun 2019.

CÂMARA MUNICIPAL DE SÃO PAULO (2016). Disponível em: http://www.camara.sp.gov.br. Acesso em: 25 abr 2016.

CARNEIRO, E. (2008). A sabedoria popular. São Paulo, Martins Fontes.

CASTELLS, M. (2003). A galáxia da Internet: reflexões sobre a internet, os negócios e a sociedade. Rio de Janeiro, Zahar.

(2013). Redes de indignação e esperança: movimentos sociais na era da internet. Rio de Janeiro, Zahar.

CIDADES COMESTÍVEIS (2015). Disponível em: http://www.cidadescomestiveis.org. Acesso em: 30 nov 2015.

CURY, J. F. (2004). História de Pinheiros. São Paulo, Subprefeitura de Pinheiros. Disponível em: http:// www.prefeitura.sp.gov.br/cidade/secretarias/subprefeituras/upload/pinheiros/pinheiros.pdf. Acesso em: 3 mar 2019 
DAMATTA, R. (1997). A casa e a rua: espaço, cidadania, mulher e morte no Brasil. Rio de Janeiro, Rocco.

FREEMAN, J. (1970). A tirania das organizações sem estrutura. Disponível em: http://info.nodo50.org. Acesso em: 3 mar 2019.

HARVEY, D. (2013). "A liberdade da cidade". In: MARICATO, E. et al. Cidades rebeldes: Passe Livre e as manifestações que tomaram as ruas do Brasil. São Paulo, Boitempo/Carta Maior.

(2014). Cidades rebeldes: do direito à cidade à revolução urbana. São Paulo, Martins Fontes.

HOFFEN, L. P. e SÄUMEL, I. (2014). Orchards for edible cities: cadmium and lead content in nuts, berries, pome and stone fruits harvested within the inner city neighbourhoods in Berlin, Germany. Ecotoxicology and Environmental Safety. Elsevier, v. 101, pp. 233-239.

HOUAISS, A. (2009). Dicionário Houaiss da língua portuguesa. Rio de Janeiro, Objetiva.

JACOBS, J. (2013). Morte e vida de grandes cidades. São Paulo, Martins Fontes.

KINUPP, V. F. e LORENZI, H. (2015). Plantas alimentícias não convencionais (PANC) no Brasil: guia de identificação, aspectos nutricionais e receitas ilustradas. Nova Odessa, Instituto Plantarum.

LADNER, P. (2011). The urban food revolution: changing the way we feed cities. Canadá, New Society.

LANGENBUCH, J. R. (1971). A estruturação da Grande São Paulo: estudo de Geografia Urbana. Tese de Doutorado. Campinas, Universidade Estadual de Campinas.

MANIER, B. (2012). Un million de révolutions tranquilles: travail, environnement, santé, argent, habitat...: comment les citoyens transforment le monde. França, LLL.

MOLLISON, B. e HOLMGREN, D. (1983). Permacultura um: uma agricultura permanente nas comunidades em geral. São Paulo, Ground.

MUDA-SP - MOVIMENTO URBANO DE AGROECOLOGIA (2015). Disponível em: http://muda.org.br. Acesso em: 30 jun 2015.

NAGIB, G. (2018). Agricultura urbana como ativismo na cidade de São Paulo. São Paulo, Annablume.

OLIVEIRA, E. M.; SOARES, M. C. e BONZI, R. S. (2012). Aplicação do desenho ambiental para a Bacia do Córrego das Corujas: potencialidades e limitações na implantação de um parque. Labverde. São Paulo, v. 1, n. 4, pp. 30-62.

PADUA, R. F. (2015). "Espaços de desindustrialização na urbanização contemporânea da metrópole". In: CARLOS, A. F. A. (org.). Crise urbana. São Paulo, Contexto.

PEZZOTTI, A. I. (1998). Vila Madalena e suas figuras notáveis. São Paulo, W. Roth.

PREFEITURA DE SÃO PAULO (2016). Disponível em: http://www.capital.sp.gov.br. Acesso em: 25 abr 2016.

REYNOLDS, R. (2009). On guerrilla gardening: a handbook for gardening without boundaries. Reino Unido, Bloomsbury.

ROLNIK. R. (2014). São Paulo. São Paulo, Publifolha.

SANTOS, M. (2004). A natureza do espaço. São Paulo, Edusp.

SCHUTZER, J. G. (2012). Cidade e meio ambiente: a apropriação do relevo no desenho ambiental urbano. São Paulo, Edusp.

SINGER, P. (2002). Introdução à economia solidária. São Paulo, Fundação Perseu Abramo. 
SMIT, J.; NASR, J. e RATTA, A. (2001). Urban agriculture: food, jobs and sustainable cities. EUA, The Urban Agriculture Network.

SOUZA, A. R. (2000). "Um instantâneo da economia solidária no Brasil”. In: SINGER, P.; SOUZA, A. R. (orgs.). A economia solidária no Brasil: a autogestão como resposta ao desemprego. São Paulo, Contexto.

SQUEFF, E. (2002). Vila Madalena: crônica histórica e sentimental. São Paulo, Boitempo.

THIOLLENT, M. (2011). Metodologia da pesquisa-ação. São Paulo, Cortez.

TRACEY, D. (2007). Guerrilla gardening: a manualfesto. Canadá, New Society.

VERRI, S. V. (2014). História imediata da Vila Madalena: uma análise das influências em 2012 da história cultural do bairro na década de 1980. Tese de Doutorado. São Paulo, Universidade de São Paulo.

Texto recebido em 3/mar/2019 Texto aprovado em 12/abr/2019 
